\title{
Demonstrating interchangeability and biosimilarity for US biosimilars
}

The US Food and Drug Administration (FDA) outlines its approach to biosimilarity and interchangeability at the 2016 Generic Pharmaceutical Association Biosimilars Council Conference. Topics covered include the FDA definition of biosimilarity, its step-wise approach to the approval process and factors/issues that should be considered when providing scientific justification for extrapolation.

Keywords: Biologicals, biosimilar, biosimilarity, interchangeability, regulation

I $\mathrm{n}$ his presentation at the 2016 Generic Pharmaceutical Association (GPhA) Biosimilars Council Conference, which was held in North Bethesda, USA on 7-8 September 2016, Dr Steven Kozlowski, Director of the Office of Biotechnology Products at the US Food and Drug Administration (FDA), outlined the agency's view with respect to biosimilarity and interchangeability [1].

The Biologics Price Competition and Innovation Act (BPCI Act) of 2009 creates an abbreviated licensure pathway for biological products shown to be biosimilar to or interchangeable with an FDA-licensed reference product.

FDA finalized its two overarching guidance documents on scientific and quality considerations in demonstrating biosimilarity, as well as two further guidances on questions and answers for biosimilars and formal meetings between FDA and sponsors in 2015 [2]. The agency has subsequently released further draft guidance documents. These cover subjects including clinical pharmacology data, reference product exclusivity, additional biosimilars questions and answers, non-proprietary naming [3], labelling, and implementation of the 'Deemed to be a License' provision of the BPCI Act. FDA also expects to issue draft guidances on both biosimilarity and interchangeability in the near future [4].

According to Dr Kozlowski, the goal of an FDA review of a biosimilar is to demonstrate biosimilarity between the proposed product and a reference product. The goal is not to independently establish the safety and effectiveness of the proposed product.

FDA defines biosimilarity as:

- that the biological product is highly similar to the reference product not- withstanding minor differences in clinically inactive components; and

- there are no clinically meaningful differences between the biological product and the reference product in terms of the safety, purity and potency of the product.

FDA has indicated that biosimilarity must first be established before any studies into interchangeability can be performed. Once biosimilarity has been established drugmakers can then decide whether to further pursue interchangeability or not. This approach, however, has raised questions as to what would happen if a product was deemed not interchangeable [5].

A biologicals application [351(a)] is a 'standalone' application that contains all information and data necessary to demonstrate that the proposed product is safe, pure and potent. In contrast, an application submitted under section $351(\mathrm{k})$, i.e. for a biosimilar, needs to demonstrate that the proposed product is biosimilar to the reference product. For licensure, a proposed biosimilar relies on (among other things) comparative data with the reference product, as well as publicly-available information regarding FDA's previous determination that the reference product is safe, pure and potent.

When considering biosimilars applications, FDA has stated that it will consider the totality of the data and information submitted in the application and that it intends to use a risk-based approach to evaluate all available data and information submitted.

To prove analytical similarity the agency considers the following to be important:

- Extensive structural and functional characterization

- Understand the molecule and function

- Identify critical quality attributes and clinically active components
- Understand the relationship between quality attributes and the clinical safety and efficacy profile aids ability to determine residual uncertainty about biosimilarity and to predict expected 'clinical similarity' from the quality data.

A step-wise approach should then be used to generate data and evaluate residual uncertainty. In this way analytical studies should be followed by animal studies, then clinical PK/PD (pharmacokinetic/ pharmacodynamic) studies, then clinical immunogenicity assessment and finally additional clinical studies.

With respect to extrapolation, FDA guidance outlines factors/issues that should be considered when providing scientific justification for extrapolation including, for example:

- The mode of action(s) in each condition of use for which licensure is sought

- The PK and bio-distribution of the product in different patient populations

- The immunogenicity of the product in different patient populations

- Differences in expected toxicities in each condition of use and patient population

- Differences between conditions of use do not necessarily preclude extrapolation

As of 31 July 2016, 62 programmes were in the Biosimilar Product Development Program. The agency has also received meeting requests to discuss the development of biosimilars for 20 different reference products.

\section{Competing interests: None.}

Provenance and peer review: Article prepared based on the presentation of Dr Steven Kozlowski, US FDA; internally peer reviewed.

Michelle Derbyshire, PhD, GaBI Online Editor

\footnotetext{
References

1. Kozlowski S. Expectations for biosimilars: an FDA perspective 2016 GPhA Biosimilars Council Conference; 8 Sep 2006; North Bethesda, MD.

2. GaBI Online - Generics and Biosimilars Initiative. US guidelines for biosimilars [www.gabionline. net]. Mol, Belgium: Pro Pharma Communications International; [cited 2016 Sep 27]. Available from: www. gabionline.net/Guidelines/US-guidelines-for-biosimilars

3. Rolandini Jensen A. US FDA proposals for naming of biologicals and labelling of biosimilars. Generics and Biosimilars Initiative Journal (GaBI Journal). 2016;5(3):140-3. doi:10.5639/gabij.2016.0503.036 References 4 to 5 can be found on page 143 .
} 


\section{Demonstrating interchangeability and biosimilarity for US biosimilars}

References (please see the full manuscript on page 139)

4. GaBI Online - Generics and Biosimilars Initiative. FDA on interchangeability and demonstrating biosimilarity [www.gabionline.net]. Mol, Belgium: Pro Pharma Communications International; [cited 2016 Sep 27]. Available from: www.gabionline.
net/Guidelines/FDA-on-interchangeability-anddemonstrating-biosimilarity

5. GaBI Online-Generics and Biosimilars Initiative. FDA gives some insight into biosimilar pathway [www.gabionline.net]. Mol, Belgium: Pro Pharma
Communications International; [cited 2016 Sep 27]. Available from: www.gabionline.net/Biosimilars/ News/FDA-gives-some-insight-into-biosimilar-pathway DOI: 10.5639/gabij.2016.0503.035

Copyright $\odot 2016$ Pro Pharma Communications International 